\section{Effects of drugs on the preference between electrical stimulation of the lateral hypothalamus and water'}

\author{
G. J. MOGENSON, The University of \\ Western Ontario, London, Ont., Canada
}

Rats with electrodes in the lateral hypothalamus were trained in a two-lever preference apparatus following $23 \mathrm{~h}$ of water deprivation to press for hypothalamic stimulation or water. The hypothalamic stimulation induced water intake, indicating that the electrodes were in the "drinking system." When the current intensity was optimal for self-stimulation, the animals pressed the lever that delivered hypothalamic stimulation and ignored the lever that delivered water. After reducing the current intensity, they divided their presses between the two levers. The administration of amphetamine increased lever pressing for hypothalamic stimulation and reduced lever pressing for water. The administration of phenobarbital increased lever pressing for water but reduced only slightly lever pressing for hypothalamic stimulation.

When electrical stimulation of the lateral hypothalamus was in competition with water reward, in a two-lever competition or preference test, lever-pressing for hypothalamic stimulation was observed to be the dominant response in water-deprived rats (Morgan \& Mogenson, 1966), confirming earlier observations showing that self-stimulation was dominant in a preference test with food-deprived rats (Routtenberg \& Lindy, 1965; Spies, 1965). With currents of lower intensity, however, lever-pressing for water was the dominant behavior (Morgan \& Mogenson, 1966), suggesting that the outcome of the preference test depends on the relative strength of the two alternative rewards.

In the present investigation, stimulating currents of moderate intensity were used so that the animals divided their lever responses between the two levers. Amphetamine and phenobarbital, drugs that decrease and increase water intake, respectively (Epstein, 1959; Schmidt, 1964; Teitelbaum \& Derks, 1958), were administered to see whether the relative preferences for hypothalamic stimulation and water can be modified. METHODS

A series of 20 male Wistar rats, 12-15 weeks of age, had bipolar electrodes implanted stereotaxically in the lateral hypothalamus (de Groot coordinates: A 5.0 to $5.5, \mathrm{~L} 1.6$ to $1.7, \mathrm{~V}-2.0$ to -2.5 ) according to the procedure described previously (Morgan \& Mogenson, 1966). After a minimum of 1 week, they were trained to self-stimulate. Pressing the lever in a Skinner-type box triggered a 60 -cycle ac Next, the rats were water-deprived for $23 \mathrm{~h}$ daily and trained to press a lever to deliver $.05 \mathrm{ml}$ of water reward. After 3 or 4 days, the duration of hypothalamic stimulation during self-stimulation sessions was increased to $1.2 \mathrm{sec}$ and a water tube was made available above the lever according to the procedure described previously (Mogenson \& Stevenson, 1966). With this procedure, it was possible to see whether the hypothalamic stimulation would induce water intake and thus whether the electrodes were in the drinking system of the lateral hypothalamus. Eight of the rats were induced to drink water and they were selected for the study. The volumes of water intake during 20-min sessions of hypothalamic stimulation are shown in the second column of Table 1.

The animals were then tested for $15 \mathrm{~min}$ daily after $23 \mathrm{~h}$ of water deprivation in a two-lever chamber according to the procedure described earlier (Morgan \& Mogenson, 1966). Water was available in the home cage for $45 \mathrm{~min}$ following the test session. Briefly, pressing one lever delivered electrical stimulation to the lateral hypothalamus and pressing the other lever, located 6 in. away on the same wall of the chamber, delivered the water reward. For four of the animals (Series 1), the duration constant-current stimulator for $0.5 \mathrm{sec}$. of stimulation was $0.2 \mathrm{sec}$, and for the other $0.5 \mathrm{sec}$. The current intensity was gradually reduced so that each animal distributed its presses about equally between the two levers. After the current intensity had been selected (varying from 15 to $30 \mu \mathrm{A}$ among animals) they were given several daily tests to ensure that the performance on the two levers was stable. Then injections of amphetamine sulphate $(1 \mathrm{mg} / \mathrm{kg})$, sodium phenobarbital $(30 \mathrm{mg} / \mathrm{kg})$, or physiological saline were administered 20-30 min before each test session. These dosages were selected because of their demonstrated effects on water intake (Mogenson, 1968; Mogenson, McLachlan, Wishart \& administered on two occasions, the scores in Table 1 being the average of the two tests. A minimum of 3 days elapsed between injections. The data were analyzed using the Friedman two-way analysis of variance by ranks.

At the termination of the experiment, the rats were sacrificed and the location of the electrode tips determined by the examination of histological sections of the hypothalamus, cut at 25 microns and stained with cresyl violet.

\section{RESULTS}

When the current intensity of hypothalamic stimulation was set initially at 20 to $30 \mu \mathrm{A}$, the animals pressed only for hypothalamic stimulation, confirming earlier observations (Morgan \& Mogenson, 1966; Routtenberg \& Lindy, 1965; Spies, 1965). With somewhat lower current intensities $(12-20 \mu \mathrm{A})$, they pressed the water lever a good deal of the time; in some cases the number of lever presses for water equalled or exceeded the number of lever presses for hypothalamic stimulation (see Table 1, control). Subsequent work has shown that the preference for hypothalamic four animals (Series 2), the duration was Stevenson, 1969). Each drug was

Table 1

Effects of Amphetamine and Phenobarbital on Preference for Hypothalamic Stimulation and Water

\begin{tabular}{|c|c|c|c|c|}
\hline Rat & W.I. & Amphetamine & Control & Phenobarbital \\
\hline No. & $(\mathrm{m} 1 / 20 \mathrm{~min})$ & LHSt. Water & LHSt. Water & LHSt. Water \\
\hline
\end{tabular}

\section{Series 1}

1

28

313

Average

$5 \quad 1384$

$\begin{array}{lll}8 & 1384 & 0 \\ 3 & 1182 & 2\end{array}$

$\begin{array}{rrr}8 & 1182 & 2 \\ 13 & 1750 & 0\end{array}$

Series 2

$\begin{array}{rr}5 & 24 \\ 6 & 6 \\ 7 & 2 \\ 8 & 11\end{array}$

$1428 \quad .75$

.75

910

$\begin{array}{rr}910 & 134 \\ 296 & 416 \\ 1189 & 273 \\ 770 & 486 \\ 641 & 327 \\ & \\ 440 & 382 \\ 555 & 460 \\ 412 & 460 \\ 222 & 264 \\ 407 & 341\end{array}$

$\begin{array}{ll}691 & 278 \\ 123 & 482 \\ 998 & 342 \\ 510 & 798 \\ 580 & 475 \\ & \\ 423 & 900 \\ 692 & 380 \\ 130 & 790 \\ 312 & 890 \\ 382 & 740\end{array}$

The number of lever presses for electrical stimulation of the lateral hypothalamus (LHSt) and the number of lever presses for water during 15 -min test sessions following administration of amphetamine $(1 \mathrm{mg} / \mathrm{kg})$, phenobarbital $(30 \mathrm{mg} / \mathrm{kg})$ and normal saline (control). For Series 1 , the duration of hypothalamic stimulation was $0.2 \mathrm{sec}$, and for Series 2 , it was $0.5 \mathrm{sec}$. 
stimulation or water can be altered systematically by varying the intensity of the stimulating current.

The administration of the two drugs produced a marked change in the preference for hypothalamic stimulation and water. Statistical analyses demonstrated that the number of lever presses for hypothalamic stimulation was increased by amphetamine and reduced by phenobarbital (Series 1: $\lambda^{2} r=8, p<.02$; Series $2: \lambda^{2} r=6, p<.05$ ), whereas the number of lever presses for water was reduced by amphetamine and increased by phenobarbital (Series 1: $\lambda^{2} \mathrm{r}=8, \quad \mathrm{p}<.02 ; \quad$ Series $2 ; \quad \lambda^{2} \mathrm{r}=6.5$, $p<.05)$. Superficially, the change in preference appears to be somewhat greater for the animals in Series 1 than for those in Series 2 , but this is due mainly to the duration of stimulation being shorter $(0.2 \mathrm{sec}$ as compared to $0.5 \mathrm{sec})$ so that there was more opportunity for the animals in Series 1 to press the lever which controlled the hypothalamic stimulation.

The electrodes were in the lateral hypothalamus between A 4.6 and A 5.2. They were in the medial forebrain bundle either near the fornix or as much as $1 \mathrm{~mm}$ lateral to the fornix.

\section{DISCUSSION}

It has been reported that rats will self-stimulate the lateral hypothalamus and neglect basic needs for survival (Morgan \& Mogenson, 1966; Routtenberg \& Lindy, 1965; Spies, 1965). When the current intensity is optimal for self-stimulation, the motivation for seeking water by pressing a lever is weaker than the motivation-reinforcement consequences of pressing a lever to stimulate the lateral hypothalamus; the animal self-stimulates the hypothalamus and ignores the water lever (Morgan \& Mogenson, 1966). If the current intensity is reduced (see Table 1, control) or if the water is made more palatable by the addition of saccharin, glucose, or sucrose (Phillips, Morgan, \& Mogenson, 1968), the animal switches from the lever that delivers hypothalamic stimulation of optimal intensity to the one that delivers the liquid reward. Apparently, an animal's preference in these tests is a function of the relative strengths of the motivation-reinforcement consequences associated with the two levers.

In the present study, the preference behavior was changed, presumably because the two drugs employed influenced the motivation-reinforcement consequences of pressing the two levers. Amphetamine has been shown to increase the reinforcement of hypothalamic stimulation (Mogenson, 1968; Stein, 1964) and to decrease the motivation to drink water when it is elicited by deprivation (Epstein, 1959) or by electrical stimulation of the lateral hypothalamus (Mogenson, 1968). Therefore, the animal's preference shifts because of reduced motivation for water reward coupled with an enhanced motivation for hypothalamic stimulation. On the other hand, for phenobarbital, which has little, if any, effect on self-stimulation of the hypothalamus(Olds, Killam, \& Eiduson, 1957), the change in preference is apparently due to its enhancing the motivation for water (Mogenson, McLachlan, Wishart, \& Stevenson, 1969; Schmidt, 1964). Apparently, amphetamine and phenobarbital both influence the integrative-control mechanisms for the regulation of water balance, whereas amphetamine, but not phenobarbital, influences the mechanisms that subserve brain self-stimulation.

\section{REFERENCES}

EPSTEIN, A. N. Suppression of eating and drinking by amphetamine and other drugs in normal and hyperphagic rats. Journal of Comparative \& Physiological Psychology, 1959, 52, 37-45.

MOGENSON, G. J. Effects of amphetamine on self-stimulation and induced drinking. Physiology \& Behavior, 1968, 3, 133-136.

MOGENSON, G. J., MCLACHLAN, R., WISHART, T., \& STEVENSON, J. A. F. Effects of phenobarbital on water intake of rats with lesions of the ventromedial hypothalamus or septum. Federation Proceedings, 1969, 28, 648 .

MOGENSON, G. J., \& STEVENSON, J. A. F. Drinking and self-stimulation with electrical stimulation of the lateral hypothalamus. Physiology \& Behavior, 1966, 1, 251-254.
MORGAN, C.W., \& MOGENSON, G. J. Preference of water-deprived rats for stimulation of the lateral hypothalamus rather than water. Psychonomic Science, 1966, 6, 337-338.

OLDS, 3., KILLAM, K. . ., \& EIDUSON, S. liffects of tranquilizers on self-stimulation of the brain. In S. Garettinj and V. Ghetti, (Eds.) Psychotropic drugs. New York: Elsevier, 1957 Pp. 235-243.

PHILLIPS, A. G., MORGAN, C. W., \& MOGENSON, G. J. Brain stimulation versus water, saccharin or sucrose in food and water deprived rats. Paper presented at Eastern Psychological Association, Washington, D.C. April 1968.

ROUTTENBERG, A., \& LINDY, J. Effects of availability of rewarding septal and hypothalamic stimulation on bar pressing for food under conditions of deprivation. Journal of Comparative \& Physiological Psychology, $1965,60,158-161$

SCHMIDT, H. Water intake as an index of drug action. In W. J. Wayner, (Ed.), Thirst. New York: Pergamon Press, 1964.

SPIES, G. Food versus intracranial self-stimulation reinforcement in food-deprived rats. Journal of Comparative \& Physiological Psychology, 1965 , 60, 153-157.

STEIN, L. Self-stimulation of the brain and the central action of amphetamine. Federation Proceedings, 1964, 23, 836-849.

TEITELBAUM, P., \& DERKS, P. The effect of amphetamine on forced drinking in the rat Joumal of Comparative \& Physiological Psychology, 1958, 51, 801-810.

\section{NOTE}

1. Research was supported by grants from the MRC and the NRC of Canada. The technical assistance of Mrs. Mary Dinning and the suggestions of Mr. A. G. Phillips during the preparation of the manuscript are gratefully acknowledged.

\section{Length of sleep and length of waking interrelations in the rat ${ }^{1}$}

\section{$W I L S E \quad B$. WEBB and JOYCE FRIEDMANN, University of Florida, Gainesville, Fla. 32601}

Across a $24 h$ period in a confined $E E G$ recording setting, the length of successive sleep and waking episodes in the rat showno direct relationship. These data imply a limitation to a hypothesis of sleep as a simple energy restoration or storage period.

A simple but impelling hypothesis about the function of sleep is that it serves as a period of energy storage or restoration. The sleep period may serve, under such a hypothesis, to dispose of accumulated toxins, restore depleted energy or develop and store energy for expenditure during waking, or serve a combination of these functions. From such a model, it would follow that the energy expenditure during the waking period would predict the length of the subsequent sleep period or, if the sleep period was an energy development and storage state, the length of the sleep period would predict the energy expenditure of the subsequent wake period. If the amount of energy expenditure during the waking periods was essentially equal, then the length of the waking period would be predictable from the sleep period, or vice versa.

For the purpose of exploring these predictions, the sleep of the laboratory rat provides an ideal paradigm. The rat's sleep and waking is quite episodic across a $24-\mathrm{h}$ period, with widely varying lengths of these episodes. For the nine animals reported in this study, the mean number of episodes of sleep was 67.0 , with a range from 45 to 87 